\title{
FAKTOR-FAKTOR YANG DIPERTIMBANGKAN KONSUMEN PADA PEMBELIAN SEPEDA MOTOR MEREK YAMAHA DI KOTA PALU
}

\author{
Edwin Sufriyatna \\ Wahyuningsih \\ Engky P. Nainggolan \\ Jurusan Manajemen, Fakultas Ekonomi, Universitas Tadulako \\ Email: xxxedwin30xxx@gmail.com
}

\begin{abstract}
This study aims to determine some factors considered by consumers prior to purchasing Yamaha motorcycles in Palu City. Type of study is exploratory with 105 respondents who bought Yamaha motorcycle in Palu City. Data collection techniques include observation, interview, and questionnaire. The tool for factor analysis is SPSS program 22.0. The results show that factors such as product, price, friend suggestion, promotion, product quality, service quality, advertisement, family suggestion, brand, lifestyle, brochure, and design were considered by consumers in buying Yamaha motorcycles in Palu City.
\end{abstract}

Keywords: Product, Product quality, Advertisement, Lifestyle, Brochure.

\section{ABSTRAK}

Penelitian ini bertujuan untuk mengetahui faktor-faktor apa saja yang dipertimbangkan konsumen membeli sepeda motor Yamaha di Kota Palu. Tipe penelitian penelitian ini adalah penelitian eksploratif (exploratory research), dengan sampel sebanyak 105 responden yang memutuskan membeli sepeda motor merek Yamaha di Kota Palu, dengan teknik pengumpulan data menggunakan metode observasi, wawancara dan kuesioner dan kemudian di olah menggunakan alat analisis faktor dengan program SPSS 22.0. Hasil penelitian menunjukan bahwa faktor produk, harga, saran teman, promosi, kualitas produk, kualitas pelayanan, iklan, saran keluarga, merek, gaya hidup, brosur dan desain dijadikan pertimbangan konsumen membeli sepeda motor merek Yamaha di kota Palu.

Kata Kunci: Produk, Kualitas produk, Iklan, Gaya hidup, Brosur.

\section{PENDAHULUAN}

Kemajuan teknologi sampai dengan saat ini berkembang seiring dengan penemuan dan pengembangan ilmu pengetahuan otomotif seperti kendaraan roda dua. Semakin tinggi kesadaran konsumen yang mendukung nilai-nilai kritisme dan rekayasa produk, untuk itu perusahaan perlu berinisiatif membuat desain yang dapat diterima di pasaran. Menurut Kotler dan Keller (2008:08) pasar secara tradisional merupakan tempat fisik di mana pembeli dan penjual berkumpul untuk membeli dan menjual barang. Keadaan tersebut mengakibatkan persaingan yang semakin ketat di antara perusahaan yang menawarkan jenis produk yang sama, namun dengan merek yang berbeda.

Mulai dari sarana transportasi yang sangat sederhana sebelum tahun 1990 contohnya seperti kendaraan sepeda motor yang masih menggunakan speedometer yang manual, dan sampai sarana transportasi yang mewah yang banyak kita jumpai di abad ini yang sudah memakai speedometer digital, radiator seperti mobil, karburator yang menghasilkan gas buangan dan mesin full injeksi yang tidak dapat mencemari lingkungan. Banyaknya jenis dan jumlah sarana transportasi telah banyak mengalami perkembangan yang pesat.

Bisnis sepeda motor merupakan salah satu bisnis yang ketat akan persaingannya. Tidak hanya sebagai tempat penjualan, namun banyak sekarang tempat penjualan sepeda motor atau yang biasa disebut dengan dealer sebagai tempat penjualan suku cadang, dan servis sepeda motor guna untuk memanjakan dan merawat kendaraan mereka khususnya pada sepeda motor. 
Salah satu merek yang digemari oleh sebagian masyarakat Kota Palu adalah merek Yamaha. Hal ini bisa terlihat dari banyaknya konsumen yang menggunakan sepeda motor Yamaha buatan Jepang ini, tidak hanya dari kalangan remaja-remaja pelajar, tapi orang tua juga banyak yang menggunakan sepeda motor ini. Alasan mereka membeli dan menggunakan sepeda motor Yamaha di karenakan oleh beberapa tanggapan yakni: Sebagai gaya hidup, ikut-ikutan trend, terlihat elit dan banyak tanggapan lainnya. Berdasarkan uraian di atas, penulis merasa tertarik melakukan penelitian pada fenomena tersebut yang berjudul "Faktor-faktor yang dipertimbangkan konsumen pada pembelian sepeda motor merek yamaha di kota Palu". Adapun tujuan yang ingin dicapai dengan dilaksanakannya penelitian ini adalah untuk mengetahui Faktor-Faktor Yang Dipertimbangkan Konsumen pada Pembelian Sepeda Motor Merek Yamaha di Kota Palu.

\section{KAJIAN LITERATURE DAN PENGEMBANGAN HIPOTESIS}

\section{Pengertian Pemasaran}

Menurut Philip Kotler dalam Sunyoto (2015:191) pemasaran merupakan suatu sistem total dari kegiatan bisnis yang dirancang untuk merencanakan, menentukan harga, promosi dan mendistribusikan barang-barang yang dapat memuaskan keinginan dan mencapai pasar sasaran serta tujuan perusahaan.

\section{Pengertian Merek}

Menurut American Marketing Association (AMA) dalam Tjiptono (2014:116) merek sebagai nama, istilah, tanda, simbol atau desain, atau kombinasi di antaranya, yang dimaksudkan untuk mengidentifikasi barang dan jasa dari satu penjual atau sekelompok penjual dan membedakannya dari barang dan jasa para pesaingnya.

\section{Pengertian Perilaku konsumen}

Menurut Kotler dan Keller (2008:166) Perilaku konsumen adalah studi tentang bagaimana individu, kelompok, dan organisasi memilih, membeli, menggunakan, dan bagaimana barang, jasa, ide, atau pengalaman untuk memuaskan kebutuhan dan keinginan mereka.

\section{Proses Keputusan Pembelian Konsumen}

Melakukan pengambilan keputusan konsumen sebagai suatu pemecahan masalah, yang harus dilakukan mengasumsi bahwa konsumen memiliki sasaran yang ingin dicapai atau dipuaskan. Seorang konsumen menganggap sesuatu merupakan masalah karena apa yang diinginkannya belum bisa tercapai. Konsumen membuat keputusan perilaku mana yang dilakukan untuk dapat mencapai sasaran, lalu mereka memecahkan masalahnya. para konsumen harus melalui seluruh lima urutan tahap: pengenalan masalah, pencarian informasi, evaluasi alternatif, keputusan pembelian, dan perilaku pasca pembelian ketika membeli atau memilih produk. 


\section{Kerangka Pemikiran}

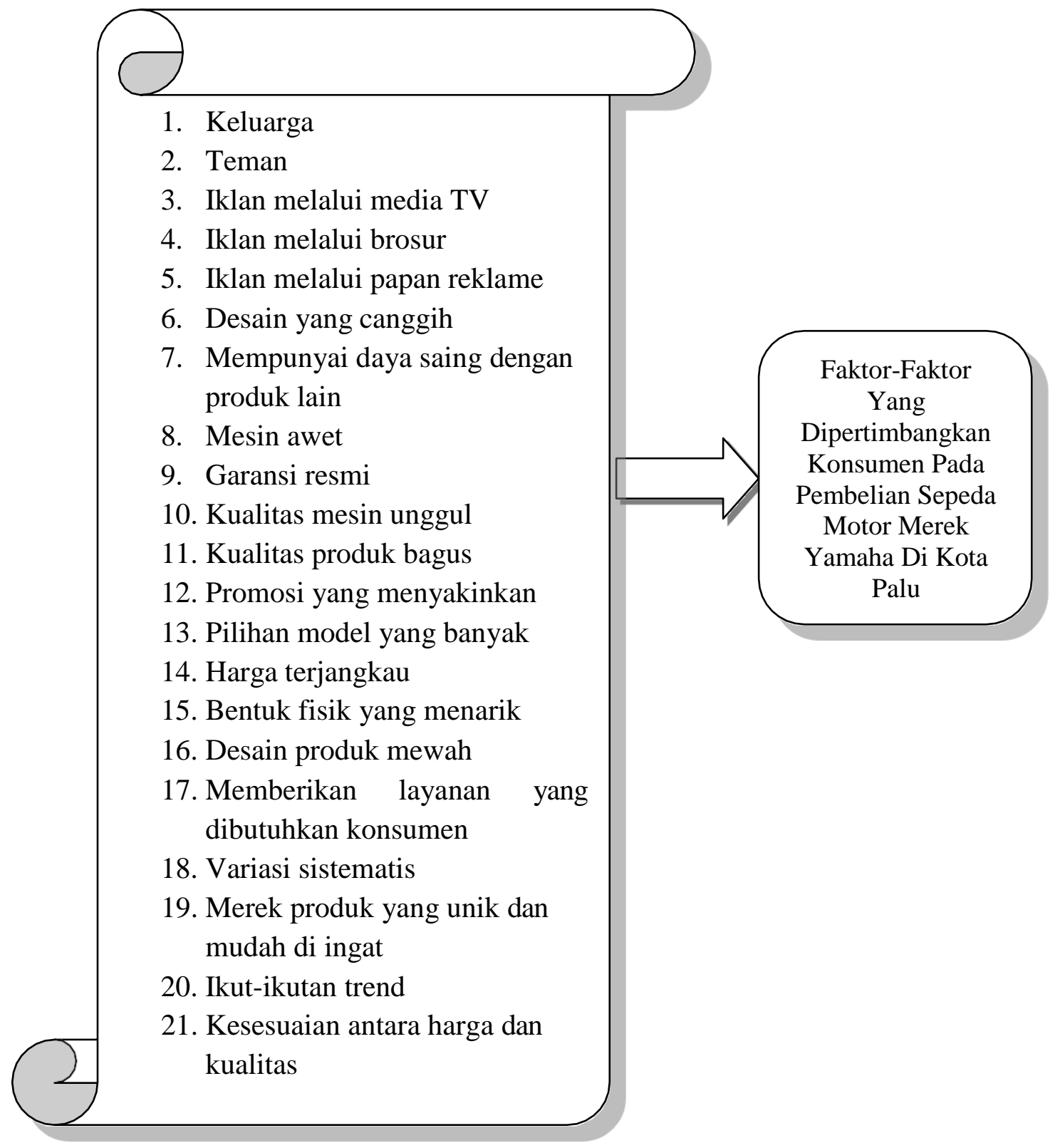

\section{Gambar 1.Kerangka Pemikiran}

\section{METODE PENELITIAN}

Penelitian ini didesain secara kuantitatif. Untuk memperoleh data-data yang dibutuhkan, penelitian ini menggunakan beberapa teknik dalam pengumpulan data-data antara lain sebagai berikut:

1. Observasi adalah metode pengumpulan data dengan cara melakukan pengamatan secara langsung untuk mengetahui keputusan konsumen, dalam hal ini konsumen yang membeli dan menggunakan sepeda motor Yamaha di Kota Palu.

2. Wawancara adalah metode pengumpulan data yang dilakukan dengan melakukan tatap muka dan tanya jawab dengan responden secara langsung. Dalam hal ini yang menjadi responden adalah konsumen yang membeli dan menggunakan sepeda motor Yamaha di Kota Palu.

3. Kuesioner adalah pengumpulan data dengan menggunakan daftar pertanyaan yang terstruktur yang akan diberikan kepada responden yang membeli dan menggunakan sepeda motor Yamaha di Kota Palu. 
Selanjutnya mmenurut Sugiyono (2014:115) pengertian populasi adalah wilayah generalisasi yang terdiri dari obyek, atau subyek yang mempunyai kuantitas dan karakteristik tertentu yang ditetapkan oleh peneliti untuk dipelajari dan kemudian ditarik kesimpulannya. Populasi merupakan jumlah keseluruhan dari subjek-subjek yang karakteristiknya akan diduga. Populasi dalam penelitian ini adalah mencakup seluruh konsumen yang membeli dan menggunakan sepeda motor Yamaha di Kota Palu Menurut Sugiyono (2014:116) sampel adalah bagian atau jumlah dan karakteritik yang dimiliki oleh populasi tersebut. Dari populasi di atas, maka teknik penarikan sampel yang digunakan dalam penelitian ini adalah Insidental Sampling. Maksud dari Insidental Sampling menurut Sugiyono (2014:122) adalah teknik penentuan sampel berdasarkan kebetulan, yaitu siapa saja yang secara kebetulan/incidental bertemu dengan peneliti dapat digunakan sebagai sampel. Menurut Malhotra (2005:92) Ukuran sampel (Sample Size) ditetapkan berdasarkan 5xparameter. Berdasarkan teori, maka untuk menentukan sampel dalam penelitian ini yaitu minimal $5 \times 21=105$ sampel.

Metode analisis yang digunakan dalam penelitian ini adalah metode analisis explanatory faktor. Pada penelitian ini pendekatan explanatory yang digunakan karena peneliti belum memiliki gambaran yang jelas tentang keberadaan akan batasan-batasan teoritik dari variabel yang digunakan pada penelitian. Analisis faktor yang digunakan untuk menentukan apakah variabel-variabel penelitian layak masuk dalam suatu faktor. Hal ini dapat dilihat dari Eigenvalue lebih dari satu atau sama dengan satu maka variabel tersebut layak masuk dalam suatu faktor. Untuk melihat besarnya masing-masing variabel dalam suatu faktor dapat dilihat dari besarnya loading masing-masing variabel, dimana menurut Malhotra dalam Samsinar (2010:36) variabel yang mempunyai nilai loading yang lebih besar atau sama dengan 0,5 dinyatakan sebagai varabel-variabel dominan yang menentukan. Secara sistematis analisis faktor dapat disajikan sebagai berikut:

$$
X i=A 1 . F 1+A 2 . F 2+A 3 . F 3+\ldots .+A i j . F m+V i . U i
$$

Keterangan:

$\mathrm{Xi} \quad=$ Variabel standar atau variabel baku

Aij $=$ Standarisasi koefisien regresi mejemuk yang dilakukan dari variable 1 atas faktor $\mathrm{j}$.

$\mathrm{F} \quad=$ Faktor umum

$\mathrm{Vi} \quad=$ Koefisien standardized loading dari variabel I pada faktor khusus $\mathrm{i}$

$\mathrm{Ui} \quad=$ Faktor khusus bagi variabel $\mathrm{i}$

$\mathrm{M} \quad$ = Banyaknya faktor umum

\section{HASIL DAN PEMBAHASAN}

\section{HASIL PENELITIAN}

\section{Tahap Pertama}

Tahap pertama pada analisis faktor adalah menilai mana saja yang dianggap layak (appropriates) untuk dimasukkan ke dalam analisis selanjutnya. Pengujian ini dilakukan dengan memasukkan semua indikator yang ada kemudian pada indikator-indikator tersebut dilakukan sejumlah pengujian. Hasil pengujian analisis tahap pertama pada 21 faktor-faktor yang dipertimbangkan konsumen pada pembelian sepeda motor merek Yamaha di Kota Palu dengan menggunakan bantuan Program Komputer SPSS versi 22.

Pada tahap pertama ini adalah dengan memeriksa nilai Eigenvalues dari analisis faktor yang telah dilakukan. Eigenvalues pada tahap ini menunjukkan bahwa seluruh indikator yang dianalisis terbentuk 6 (enam) faktor. Hal ini dapat dilihat berdasarkan Tabel Eigenvalues yang menunjukkan hanya 6 (enam) komponen yang memiliki Eigenvalues di atas 1.00. untuk lebih jelasnya nilai masing-masing Eigenvalues komponen dapat dilihat pada tabel 1 berikut ini: 
Tabel 1. Nilai Eigenvalues Tahap Pertama

\begin{tabular}{|c|c|c|c|c|c|c|c|c|c|}
\hline \multirow[b]{2}{*}{ Component } & \multicolumn{3}{|c|}{ Initial Eigenvalues } & \multicolumn{3}{|c|}{ Extraction Sums of Squared Loadings } & \multicolumn{3}{|c|}{ Rotation Sums of Squared Loadings } \\
\hline & Total & \% of Variance & Cumulative \% & Total & $\%$ of Variance & Cumulative \% & Total & \% of Variance & Cumulative \% \\
\hline 1 & 6,494 & 30,922 & 30,922 & 6,494 & 30,922 & 30,922 & 3,347 & 15,940 & 15,940 \\
\hline 2 & 2,161 & 10,292 & 41,215 & 2,161 & 10,292 & 41,215 & 2,339 & 11,138 & 27,078 \\
\hline 3 & 1,475 & 7,023 & 48,237 & 1,475 & 7,023 & 48,237 & 2,213 & 10,539 & 37,617 \\
\hline 4 & 1,309 & 6,233 & 54,471 & 1,309 & 6,233 & 54,471 & 2,160 & 10,287 & 47,904 \\
\hline 5 & 1,215 & 5,784 & 60,254 & 1,215 & 5,784 & 60,254 & 1,875 & 8,929 & 56,833 \\
\hline 6 & 1,122 & 5,342 & 65,596 & 1,122 & 5,342 & 65,596 & 1,840 & 8,764 & 65,596 \\
\hline 7 & ,874 & 4,161 & 69,757 & & & & & & \\
\hline 8 & 803 & 3,825 & 73,581 & & & & & & \\
\hline 9 &, 727 & 3,463 & 77,045 & & & & & & \\
\hline 10 & 666 & 3,170 & 80,214 & & & & & & \\
\hline 11 &, 595 & 2,835 & 83,049 & & & & & & \\
\hline 12 &, 548 & 2,609 & 85,658 & & & & & & \\
\hline 13 & 484 & 2,306 & 87,964 & & & & & & \\
\hline 14 & ,432 & 2,058 & 90,023 & & & & & & \\
\hline 15 & 424 & 2,020 & 92,043 & & & & & & \\
\hline 16 & ,397 & 1,889 & 93,932 & & & & & & \\
\hline 17 & 298 & 1,420 & 95,352 & & & & & & \\
\hline 18 & 274 & 1,303 & 96,655 & & & & & & \\
\hline 19 & 244 & 1,163 & 97,818 & & & & & & \\
\hline 20 & 235 & 1,117 & 98,934 & & & & & & \\
\hline 21 & 224 & 1,066 & 100,000 & & & & & & \\
\hline
\end{tabular}

Berdasarkan tabel 1, diketahui bahwa terdapat 6 (enam) faktor yang terbentuk pada analisis tahap pertama. Tahap selanjutnya adalah pengujian atas matriks faktor. Pengujian terhadap matriks faktor dilakukan dengan membandingkan nilai Component Matrikx pada setiap variabel dengan nilai loading factor. Apabila ditemukan nilai matriks faktor lebih kecil dari nilai loading factor maka faktor tersebut dikeluarkan dari proses factoring karena variabel tidak dapat secara nyata membentuk sebuah faktor.

Nilai loading factor atau pembatas (cut off point) agar sebuah variabel dapat secara nyata termasuk sebuah faktor, dari data 105 responden yang diperoleh pada penelitian ini adalah sebesar 0,5. Untuk lebih jelasnya nilai matriks faktor yang dibandingkan dengan nilai loading factor sebesar 0,5 untuk secara nyata dapat termasuk sebuah faktor, dapat termasuk sebuah faktor, dapat dilihat tabel 2 berikut:

Tabel 2. Komponen Matriks Tahap Pertama

\begin{tabular}{|l|r|r|r|r|r|r|}
\hline & \multicolumn{7}{|c|}{ Component } \\
\cline { 2 - 7 } & 1 & 2 & 3 & 4 & \multicolumn{1}{|c|}{5} & \multicolumn{1}{c|}{. } \\
\hline F1 &, 673 &,- 014 &,- 044 &, 215 &,- 004 &,- 240 \\
F2 &, 600 &,- 400 &, 034 &,- 158 &, 266 &,- 205 \\
F3 &, 630 &, 006 &,- 362 &, 287 &,- 065 &, 072 \\
F4 &, 417 &, 520 &,- 358 &,- 415 &, 176 &, 015 \\
F5 &, 481 &, 354 &,- 201 &, 485 &,- 246 &, 176 \\
F6 &, 701 &, 083 &,- 145 &,- 331 &,- 100 &,- 180 \\
F7 &, 519 &, 001 &, 160 &,- 025 &,- 536 &,- 373 \\
F8 &, 496 &, 129 &, 155 &,- 142 &,- 648 &, 121 \\
F9 &, 381 &, 558 &, 278 &, 284 &, 052 &, 305 \\
F10 &, 564 &, 279 &, 218 &,- 367 &, 095 &,- 294 \\
F11 &, 665 &,- 220 &, 259 &,- 302 &,- 091 &, 235 \\
F12 &, 589 &,- 271 &,- 368 &, 011 &, 038 &, 123 \\
F13 &, 407 &, 542 &,- 330 &, 138 &, 116 &,- 055 \\
F14 &, 574 &,- 394 &, 077 &, 073 &, 094 &, 237 \\
F15 &, 544 &,- 407 &,- 177 &,- 163 &,- 043 &, 381 \\
F16 &, 712 &,- 193 &, 227 &,- 010 &, 125 &, 381 \\
F17 &, 705 &,- 173 &,- 175 &, 113 &,- 056 &,- 276 \\
F18 &, 306 &, 572 &, 421 &,- 207 &, 197 &, 184 \\
F19 &, 622 &, 092 &, 314 &, 237 &, 213 &,- 154 \\
F20 &, 357 &,- 232 &, 470 &, 386 &, 166 &,- 239 \\
F21 &, 468 &, 019 &,- 223 &, 029 &, 394 &,- 097 \\
\hline
\end{tabular}


Berdasarkan tabel 2, dapat diketahui bahwa terdapat beberapa indikator yang memiliki nilai matriks faktor di bawah nilai loading factor.

\section{Tahap Kedua}

Pengujian selanjutnya pada tahap kedua ini adalah dengan memeriksa nilai Eigenvalues dari analisis faktor yang telah dilakukan pada tahap pertama. Eigenvalues pada tahap pertama menunjukkan bahwa seluruh indikator yang dianalisis terbentuk faktor 4 (empat) faktor. Hal ini dapat dilihat berdasarkan Tabel Eigenvalues yang menunjukkan bahwa komponen yang memiliki nilai Eigenvalues diatas 1.00. Untuk lebih jelasnya perubahan nilai masing-masing Eigenvalues komponen dapat dilihat pada tabel 3 berikut:

Tabel 3. Nilai Eigenvalues Tahap Kedua

\begin{tabular}{|c|c|c|c|c|c|c|c|c|c|}
\hline \multicolumn{10}{|c|}{ Total Variance Explained } \\
\hline \multirow[b]{2}{*}{ Component } & \multicolumn{3}{|c|}{ Initial Eigenvalues } & \multicolumn{3}{|c|}{ Extraction Sums of Squared Loadings } & \multicolumn{3}{|c|}{ Rotation Sums of Squared Loadings } \\
\hline & Total & $\begin{array}{c}\% \text { of } \\
\text { Variance }\end{array}$ & $\begin{array}{c}\text { Cumulative } \\
\%\end{array}$ & Total & $\%$ of Variance & Cumulative \% & Total & $\%$ of Variance & Cumulative \% \\
\hline 1 & 5,766 & 33,918 & 33,918 & 5,766 & 33,918 & 33,918 & 3,221 & 18,947 & 18,947 \\
\hline 2 & 2,051 & 12,065 & 45,983 & 2,051 & 12,065 & 45,983 & 2,297 & 13,513 & 32,460 \\
\hline 3 & 1,302 & 7,658 & 53,640 & 1,302 & 7,658 & 53,640 & 2,121 & 12,476 & 44,936 \\
\hline 4 & 1,087 & 6,394 & 60,034 & 1,087 & 6,394 & 60,034 & 2,012 & 11,834 & 56,770 \\
\hline 5 & 1,060 & 6,237 & 66,272 & 1,060 & 6,237 & 66,272 & 1,615 & 9,502 & 66,272 \\
\hline 6 &, 827 & 4,864 & 71,136 & & & & & & \\
\hline 7 & ,730 & 4,295 & 75,431 & & & & & & \\
\hline 8 & 685 & 4,027 & 79,457 & & & & & & \\
\hline 9 & ,599 & 3,521 & 82,978 & & & & & & \\
\hline 10 &, 506 & 2,976 & 85,954 & & & & & & \\
\hline 11 & , 488 & 2,873 & 88,827 & & & & & & \\
\hline 12 & 451 & 2,656 & 91,483 & & & & & & \\
\hline 13 & 361 & 2,123 & 93,606 & & & & & & \\
\hline 14 &, 305 & 1,791 & 95,397 & & & & & & \\
\hline 15 & 283 & 1,665 & 97,062 & & & & & & \\
\hline 16 & ,267 & 1,573 & 98,635 & & & & & & \\
\hline 17 & 232 & 1,365 & 100,000 & & & & & & \\
\hline
\end{tabular}

Berdasarkan data pada tabel 3 di atas, diketahui bahwa terdapat 5 (lima) faktor yang terbentuk pada analisis yang dilakukan pada tahap kedua. Tahap selanjutnya adalah pengujian atas matriks faktor. Pengujian terhadap matriks faktor dilakukan dengan membandingkan nilai Component Matrix pada setiap indikator dengan nilai loading factor maka faktor tersebut akan dikeluarkan dari proses factoring karena indicator tidak dapat secara nyata membentuk sebuah faktor.

Nilai loading factor atau pembatas (cut off point) agar sebuah indikator dapat secara nyata termasuk faktor, dari data 105 responden yang diperoleh oleh penelitian ini adalah sebesar 0.5. Untuk lebih jelasnya nilai matriks faktor yang dibandingkan dengan nilai loading factor sebesar 0.5 untuk secara nyata dapat termasuk sebuah faktor, dan dapat dilihat pada tabel 4 berikut: 
Tabel 4. Komponen Matriks Tahap Kedua

\begin{tabular}{|c|c|c|c|c|c|}
\hline & \multicolumn{5}{|c|}{ Component } \\
\hline & 1 & 2 & 3 & 4 & 5 \\
\hline $\mathrm{F} 1$ & ,669 & ,010 &,- 164 &,- 120 &,- 251 \\
\hline $\mathrm{F} 2$ & ,628 &,- 328 & , 087 &,- 190 & , 127 \\
\hline F3 & ,622 &,- 045 &,- 359 & ,215 &,- 215 \\
\hline F4 & ,426 & ,525 &,- 361 & , 135 & 434 \\
\hline F6 & ,713 & , 112 &,- 233 &,- 188 & ,347 \\
\hline F7 & ,500 &,- 002 &,- 011 &,- 577 &,- 066 \\
\hline F9 & ,353 & ,563 & ,272 & 284 &,- 250 \\
\hline F10 & ,577 & ,366 & , 145 &,- 374 & , 176 \\
\hline F11 & ,673 &,- 177 & ,356 & ,001 & ,312 \\
\hline F12 & 612 &,- 283 &,- 325 & 264 & , 045 \\
\hline F13 & ,399, &, 514 &,- 413 & , 188 &,- 200 \\
\hline F14 & ,584 &,- 372 & ,206 & ,208 &,- 111 \\
\hline F15 & ,569 &,- 421 &,- 004 & 297 & 269 \\
\hline F16 & ,720 &,- 153 & ,387 & ,276 &,- 015 \\
\hline F17 & ,709 &,- 183 &,- 183 &,- 230 &,- 284 \\
\hline F18 & ,301 & ,654 & ,403 & , 106 & , 162 \\
\hline F19 & ,613 & ,166 & ,261 &,- 081 &,- 446 \\
\hline
\end{tabular}

Berdasarkan Tabel 4 di atas, dapat diketahui bahwa semua faktor dikatakan memenuhi syarat untuk memiliki nilai loading factor lebih dari 0.5. Tahap selanjutnya menganalisis tabel Communalities, dimana pada dasarnya adalah jumlah varians dari suatu indikator mula-mula yang bisa dijelaskan oleh faktor yang ada. Berikut tabel 5 Communalities pada tahap ini sebagai berikut:

\section{Tabel 5. Communalities}

\begin{tabular}{|l|r|r|}
\hline & Initial & Extraction \\
\hline F1 & 1,000 &, 551 \\
F2 & 1,000 &, 562 \\
F3 & 1,000 &, 611 \\
F4 & 1,000 &, 793 \\
F6 & 1,000 &, 731 \\
F7 & 1,000 &, 587 \\
F9 & 1,000 &, 658 \\
F10 & 1,000 &, 659 \\
F11 & 1,000 &, 708 \\
F12 & 1,000 &, 631 \\
F13 & 1,000 &, 669 \\
F14 & 1,000 &, 578 \\
F15 & 1,000 &, 662 \\
F16 & 1,000 &, 768 \\
F17 & 1,000 &, 703 \\
F18 & 1,000 &, 718 \\
F19 & 1,000 &, 677 \\
\hline
\end{tabular}

Setelah melalui tahap kedua diketahui bahwa nilai Komponen Matriks di atas angka loading factor sebesar 0.5, dimana dapat diartikan bahwa keseluruhan indikator telah dikatakan layak atau memenuhi syarat. Pada tahap ini terbentuk juga faktor, setelah dilakukan pengujian analisis faktor dengan melihat nilai Eigenvalues yang terbentuk yaitu diatas nilai 1.00, maka selanjutnya adalah memeriksa faktorfaktor yang memenuhi syarat nilai loading 0.5 dengan indikator pembentuknya pada hasil pengujian analisis faktor dengan melihat tabel Rotated Component Matrix sebagai berikut: 
Sufriyatna, E.

Tabel 6. Rotated Component Matrix

\begin{tabular}{|l|r|r|r|r|r|}
\hline & \multicolumn{6}{|c|}{ Component } \\
\cline { 2 - 6 } & 1 & 2 & 3 & 4 & \multicolumn{1}{c|}{5} \\
\hline F1 &, 246 &, 454 &, 513 &, 136 &, 053 \\
F2 &, 567 &, 470 &, 094 &,- 081 &, 060 \\
F3 &, 312 &, 128 &, 689 &, 051 &, 144 \\
F4 &, 029 &, 051 &, 233 &, 225 &, 827 \\
F6 &, 337 &, 480 &, 227 &, 026 &, 579 \\
F7 &, 087 &, 752 &, 107 &, 007 &, 051 \\
F9 &, 035 &,- 013 &, 223 &, 777 &, 060 \\
F10 &, 125 &, 613 &,- 023 &, 369 &, 362 \\
F11 &, 722 &, 332 &,- 101 &, 191 &, 174 \\
F12 &, 535 &, 056 &, 523 &,- 148 &, 214 \\
F13 &,- 157 &, 044 &, 623 &, 342 &, 371 \\
F14 &, 679 &, 135 &, 242 &, 096 &,- 176 \\
F15 &, 764 &, 003 &, 181 &,- 125 &, 174 \\
F16 &, 755 &, 153 &, 160 &, 384 &,- 044 \\
F17 &, 322 &, 567 &, 525 &,- 019 &,- 046 \\
F18 &, 047 &, 085 &,- 161 &, 758 &, 328 \\
F19 &, 226 &, 440 &, 342 &, 520 &,- 212 \\
\hline
\end{tabular}

Berdasarkan tabel 6, disimpulkan bahwa semua faktor dikatakan memenuhi syarat atau memiliki nilai loading faktor lebih dari 0.5. Proses selanjutnya dari analisis faktor adalah proses penamaan faktor dari faktor yang dikatakan layak setelah melewati beberapa hasil uji. Pada proses penamaan ini dilakukan secara berurutan dari faktor yang memiliki nilai Eigenvalues terbesar hingga terkecil.

Tabel 7. Ringkasan Faktor dan Indikator yang Membentuknya

\begin{tabular}{|c|l|c|c|}
\hline Faktor & \multicolumn{1}{|c|}{ Indikator } & Loading & $\begin{array}{c}\text { Total } \\
\text { Loading }\end{array}$ \\
\hline & 1. F15 bentuk fisik yang menarik & 0,764 & \\
Produk, Harga, & 2. F16 desain produk mewah & 0,755 & \\
Saran teman, dan & 4. F11 kualitas produk bagus & 0,722 & 4,022 \\
Promosi & 5. F2 saran teman & 0,679 & \\
& 6. F12 promosi yang meyakinkan & 0,567 & \\
\hline \multirow{3}{*}{ Kualitas produk } & 1.F7 mempunyai daya saing dengan produk lain & 0,535 & \\
dan Kualitas & 2.F10 kualitas mesin unggul & & \\
pelayanan & 3.F17 memberikan layanan yang dibutuhkan & 0,752 & \\
& konsumen & 0,567 & \\
\hline \multirow{2}{*}{$\begin{array}{c}\text { Iklan dan Saran } \\
\text { keluarga }\end{array}$} & 1. F3 iklan melui media TV & & \\
& 2. F13 pilihan model yang banyak & 0,689 & \\
\hline & 1.F9 garansi resmi & 0,623 & \\
Merek dan Gaya & 2.F18 variasi sistematis & 0,513 & \\
hidup & 3.F19 merek produk yang unik dan mudah di & 0,777 & \\
& ingat & 0,758 & \\
\hline Brosur dan & 1. F4 iklan melalui brosur & 0,52 & \\
Desain & 2. F6 desain yang canggih & 0,579 & \\
\hline
\end{tabular}




\section{PEMBAHASAN}

Berdasarkan tabel di atas dapat diketahui penamaan fakor yang telah terbentuk. Untuk pembahasan dapat di jelaskan sebagai berikut:

\section{Faktor 1. (Produk, Harga, Saran Teman dan Promosi)}

Faktor pertama memiliki nilai Eigenvalues sebesar 5.766 dan nilai total loading sebesar 4,022. faktor ini terbentuk menjadi 6 (enam) indikator, yaitu F2 (saran teman) dengan faktor loading sebesar 0.764, F11 (kualitas produk bagus) dengan faktor loading sebesar 0.722, F12 (promosi yang meyakinkan) dengan faktor loading sebesar 0.535, F14 (harga terjangkau) dengan faktor loading sebesar 0.679, F15 (bentuk fisik yang menarik) dengan faktor loading sebesar 0.764, dan F16 (desain produk mewah) dengan faktor loading sebesar 0.755 .

Hasil penelitian sesuai dengan temuan penelitian Putra (2016) bahwa produk, Harga dan promosi berpengaruh terhadap keputusan pembelian sepeda motor Kawasaki yang dikarenakan produk sepeda motor Kawasaki yang ditawarkan akan disukai oleh konsumen karena dirasa akan memberikan manfaat-manfaat bagi pemakainya sehingga akan menarik minat mereka untuk membeli produk tersebut, harga merupakan salah satu faktor penting dalam menarik minat konsumen untuk membeli, Promosi yang dilakukan terus-menerus akan membentuk image sepeda motor Kawasaki yang kuat dalam konsumen. Tetapi penelitian ini berbeda dengan temuan penelitian Wahyudi (2014) yang menyatakan bahwa saran teman tidak mempengaruhi konsumen membeli motor Harley Davidson yang dikarenakan dalam penelitian ini saran dari keluargalah yang paling banyak memilih di bandingkan dengan saran teman.

\section{Faktor 2. (Kualitas Produk dan Kualitas Pelayanan)}

Faktor kedua memiliki nilai Eigenvalues sebesar 2.051 dan nilai total loading sebesar 1,932. Faktor ini terbentuk menjadi 3 (tiga) indikator, yaitu F7 (mempunyai daya saing dengan produk lain) dengan faktor loading sebesar 0.752, F10 (kualitas mesin unggul) dengan faktor loading sebesar 0.613, dan F17 (memberikan layanan yang dibutuhkan konsumen) dengan faktor loading sebesar 0.567.

Hasil penelitian sesuai dengan temuan penelitian Rizan dan Andika (2011) bahwa kualitas produk dan kualitas pelayanan berpengaruh terhadap kepuasan pelanggan suzuki pada dealer Fatmawati di Jakarta selatan yang dikarenakan kualitas produk adalah bagian motor Suzuki yang melekat dan memberikan suatu manfaat kepada pelanggan yang menggunakan motor Suzuki. Bagian-bagian itu antara lain: kualitas mesin motor Suzuki dan bentuk bodi motor Suzuki, kualitas pelayanan mempunyai pertimbangan khusus dari konsumen terhadap pemilihan dealer Suzuki Fatmawati, Jakarta Selatan sebagai tempat untuk melakukan service motor Suzuki. Hasil penelitain juga sesuai dengan penelitian Woy, Mandey, dan Soepeno (2014) bahwa kualitas produk merupakan salah satu faktor yang dipertimbangkan terhadap keputusan pembelian konsumen pada motor Honda di PT. Nusantara Surya Sakti cabang Manado.

\section{Faktor 3. (Iklan dan Saran Keluarga)}

Faktor ketiga memiliki nilai Eigenvalues sebesar 1.302 dan nilai total loading sebesar 1,825. Faktor ini terbentuk dari 3 (tiga) indikator, yaitu F1 (saran keluarga) dengan faktor loading sebesar 0.513, F3 (iklan melalui media TV) dengan faktor loading sebesar 0.689, dan F13 (pilihan model yang banyak) dengan faktor loading sebesar 0.623 .

Hasil penelitian yang sesuai dengan saran keluarga yaitu temuan penelitian Wahyudi dan Prawita (2014) bahwa saran keluarga merupakan salah satu faktor yang mempengaruhi perilaku konsumen dalam memilih sepeda motor Harley Davidson yang dikarenakan keluarga mempunyai peran terbesar dalam mempengaruhi individu dalam pembelian suatu produk. Hasil penelitian juga sesuai dengan penelitian kotler dan amstrong (2008:150) bahwa iklan merupakan semua bentuk terbayar dari 
presentasi nonpribadi dan promosi ide, barang, atau jasa oleh sponsor tertentu. yang menyatakan iklan televisi seperti coca-cola yang mahal ditujukan terutama untuk membangun dan memelihara hubungan merek coca-cola dari pada menginformasikan atau membujuk pelanggan untuk membeli dalam jangka pendek.

\section{Faktor 4. (Merek dan Gaya Hidup)}

Faktor keempat memiliki nilai Eigenvalues sebesar 1.087 dan nilai total loading sebesar 2,055. Faktor ini terbentuk dari 3 (tiga) indikator, yaitu F9 (garansi resmi) dengan faktor loading sebesar 0.777, F18 (variasi sistematis) dengan faktor loading sebesar 0.758, dan F19 (merek produk yang unik dan mudah di ingat) dengan faktor loading sebesar 0.520 .

Hasil penelitian yang ditemukan sesuai dengan temuan penelitian Adnan (2011) yang meneliti tentang Faktor-faktor yang Mempengaruhi Keputusan Konsumen dalam Membeli Sepeda Motor Honda Vario (Studi Kasus di Lhoksumawe), hasil penelitiannya menunjukkan bahwa merek merupakan faktor yang berpengaruh terhadap keputusan konsumen dalam membeli sepeda motor merek Honda Vario. Berbeda dengan penelitian menurut Jariah (2012) menyatakan bahwa gaya hidup tidak mempunyai pengaruh terhadap keputusan pembelian sepeda motor Yamaha yang dikarenakan gaya hidup bukan faktor yang mempengaruhi keputusan pembelian sepeda motor Yamaha di Lumajang.

\section{Faktor 5. (Brosur dan Desain)}

Faktor kelima memiliki nilai Eigenvalues sebesar 1.060 dan nilai total loading sebesar 1,406. Faktor ini terbentuk dari 2 (dua) indikator, yaitu F4 (iklan melalui brosur) dengan faktor loading sebesar 0.827, dan F6 (desain yang canggih) dengan faktor loading sebesar 0.579. Hasil penelitian yang sesuai dengan desain yaitu temuan penelitian Puspawaty (2012) bahwa desain merupakan faktor yang dipertimbangkan konsumen pada pembelian sepeda motor Honda Vario pada CV. Citra Sentosa Mandiangin. Dalam hal ini desain sepeda motor Yamaha merupakan desain yang canggih. Dimana konsumen menilai baik ataupun tidaknya tentang atribut yang dimaksudkan dalam kecanggihan sepeda motor Yamaha tersebut.

Hasil penelitian juga sesuai dengan Rahmadhani (2013) bahwa brosur merupakan salah satu faktor yang dipertimbangkan pada minat beli masyarakat terhadap sepeda motor Honda yang dikarenakan pada masyarakat di kecamatan Tampan, Pekanbaru lebih tertarik dan percaya pada brosur yang di edarkan berdasarkan dari hasil dan data yang telah dikumpulkan.

\section{KESIMPULAN DAN SARAN}

\section{Kesimpulan}

Hasil analisis faktor yang dilakukan dengan melalui tahapan-tahapan pengujian dengan menggunakan 21 indikator dan diperoleh data dari 105 responden yang digunakan sebagai sampel penelitian, ditemukan bahwa ada 5 (lima) faktor yang dipertimbangkan konsumen terhadap keputusan pembelian sepeda motor merek Yamaha di Kota Palu yaitu:

1. produk, harga, saran teman dan promosi

2. kualitas produk dan kualitas pelayanan

3. Iklan dan saran keluarga

4. Merek dan gaya hidup

5. Brosur dan desain.

\section{Saran}

Sepeda motor Yamaha adalah salah satu dari sekian banyak produk sepeda motor yang ada dengan berbagai macam jenis dan model yang bervarian. Dalam hal ini penulis ingin memberikan beberapa 
saran untuk perusahaan sepeda motor Yamaha agar ke depannya bisa lebih berkembang, yaitu sebagai berikut:

1. Disarankan kepada perusahaan sepeda motor Yamaha agar lebih meningkatkan dalam sistem pembrosuran dan desainnya, agar tetap menambah jumlah konsumen yang akan membeli sepeda motor Yamaha, karena berdasarkan hasil penelitian ini faktor-faktor yang dominan dipertimbangkan konsumen membeli sepeda motor merek Yamaha yaitu produk, harga, saran teman, dan promosi.

2. Disarankan kepada peneliti selanjutnya yang tertarik untuk meneliti dengan objek yang sama agar lebih memperhatikan indikator-indikator yang dipertimbangkan dan tahapan dalam mengolah data penelitian, agar hasil penelitian yang dihasilkan lebih maksimal.

\section{REFERENSI}

Adnan (2011), Analisis Faktor-faktor yang Mempengaruhi Keputusan Konsumen dalam Membeli Sepeda Motor Honda Vario (Studi Kasus di Lhoksumawe), Medan, Tesis Ilmu Manjemen, Porgram Pascasarjana USU, Medan.

Jariah, Ainun (2012), Analisis Faktor-Faktor Pribadi Yang Mempengaruhi Keputusan Pembelian Sepeda Motor Yamaha Di Lumajang, Universitas STIE Widya Gama Lumajang, Jurnal Wiga, Volume 2, No. 2, Halaman 1-18.

Kotler, Philip Dan Kevin Lane Keller, 2008, Manajemen Pemasaran, Edisi Ketiga Belas, Jilid I. Jakarta: Penerbit Erlangga.

Malhotra, Nares K., 2005, Riset Pemasaran : Pendekatan Terapan, Jilid 1, Edisi Keempat. Jakarta: PT. Indeks.

Puspawaty, Evvy (2006), Analisa Faktor-Faktor Yang Mempengaruhi Keputusan Pembelian Motor Honda Vario Pada CV. Citra Sentosa Mandiangin, Fakultas Ekonomi Universitas Jambi, Jurnal Digest Marketing, Volume 1, No. 3, Halaman 185-191.

Putra, Alif Pratama, dan Agustin, Sasi (2016), Pengaruh Bauran Pemasaran Terhadap keputusan Pembelian Sepeda Motor Kawasaki, Sekolah Tinggi Ilmu Ekonomi Indonesia (STIESIA) Surabaya, Jurnal Ilmu Dan Riset Manajemen, Volume 5, No. 6, Halaman 1-18.

Rahmadhani, Asih (2013), Faktor-Faktor Yang Dipertimbangkan Pada Minat Beli Masyarakat Terhadap Sepeda Motor Honda, Fakultas Sains dan Teknologi Universitas Islam Negeri Sultan Syarif Kasim Riau Pekanbaru, Tesis, Fakultas Sains Dan Teknologi Universitas Islam Negeri Sultan Syarif Kasim Riau, Pekanbaru.

Rizan, Mohamad dan Fajar Andika (2011), Pengaruh Kualitas Produk Dan Kualitas Pelayanan Terhadap Kepuasan Pelanggan (Survei Pelanggan Suzuki, Dealer Fatmawati, jakarta Selatan), Fakultas Ekonomi Universitas Negeri Jakarta, Jurnal Riset Manajemen Sains Indonesia (JRMSI), Volume 2, No. 1, Halaman 130-150.

Samsinar (2010), Faktor-Faktor Yang Dipertimbangkan Mahasiswa Fakultas Ekonomi Untad Menggunakan Internet Dikota Palu, Skripsi Fakultas Ekonomi, Universitas Tadulako, Palu.

Sugiyono, 2014, Metode Penelitian Bisnis. Bandung: Alfabeta.

Sunyoto, Danang, 2015, Perilaku Komsumen Dan Pemasaran, Cetakan Pertama. Jakarta: Caps. Wahyudi, Dedi, dan Prawita, Sri (2014), Fakkor-faktor Yang Mempengaruhi Perilaku Konsumen

Dalam Memilih Sepeda Motor Harley Davidson, Fakultas Politeknik LP3I Medan, Jurnal Ilman, Volume 1, No. 1, Halaman 83-92.

Woy, A.D Meigy, Mandey, Silvya, Soepeno, Djurwaty (2014), Kualitas Produk, Strategi Harga, Promosi Terhadap Keputusan Pembelian Motor Honda Pada PT. Nusantara Surya Sakti Manado, Jurnal EMBA, Volume 2, No. 3, Halaman 1483-1494.

Website:

http://abirahmanprasetyo.blogspot.co.id/2013/11/sejarah-perusahaan-yamaha.html 
Sufriyatna, E.

http://otomotifnet.com/Motor/Bisnis/Data-Lengkap-Penjualan-Motor-Mei-2016-Honda-Kuasai-PasarSuzuki-Naik\#

https://www.hasbihtc.com/sejarah-motor-yamaha-dari-masa-ke-masa.html

https://www.google.com/search?q=gambaran+umum+perusahaan+sepeda+motor+yamaha\&ei=elbLW KXJEIOAvgSK95HICg\&start=30\&sa=N 